
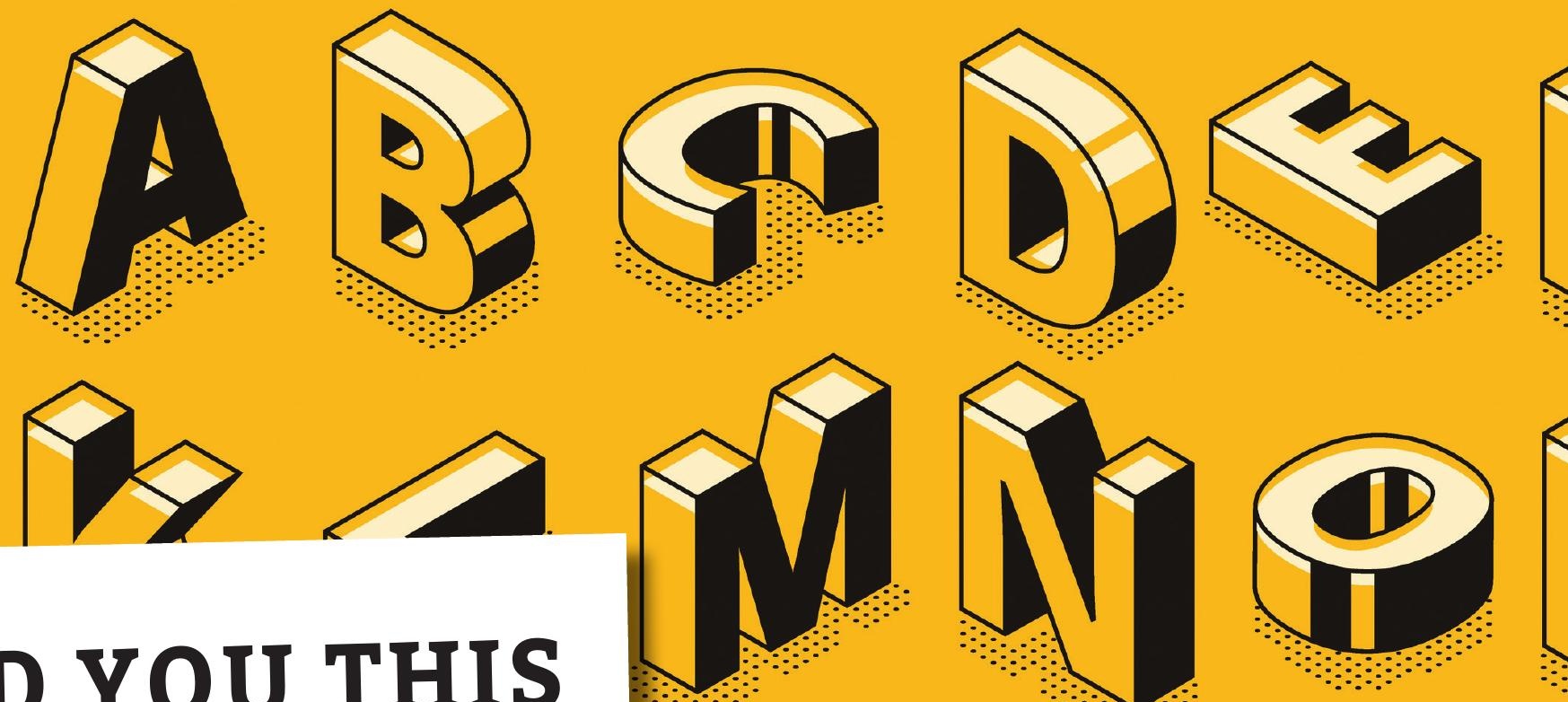

\title{
DID YOU THIS READ RIGHT?
}

READING IS PERHAPS THE MOST COMPLEX SKILL WE LEARN; IT INVOLVES TURNING INTRICATE SEQUENCES OF SYMBOLS INTO SOMETHING COHERENT INSIDE OUR HEAD. DR JONATHAN GRAINGER OF THE COGNITIVE PSYCHOLOGY LAB, FRENCH NATIONAL CENTRE FOR SCIENTIFIC RESEARCH (CNRS) AND AIXMARSEILLE UNIVERSITY, FRANCE, IS INTENT ON UNCOVERING EXACTLY HOW THIS PROCESS WORKS, THROUGH CLEVER PSYCHOLOGICAL EXPERIMENTATION

\section{TALK LIKE A COGNITIVE PSYCHOLOGIST}

\section{COGNITIVE PSYCHOLOGY - the}

science of how the mind works, covering mental processes such as memory, language and reasoning

\section{COGNITIVE NEUROSCIENCE - the}

science of understanding the neural basis of mental processes

COMPREHENSION - being able to understand and interpret something

\section{COMPUTATIONAL MODEL - a model} that can be implemented on a computer with an aim to simulate a real-world system
DECODING - in the psychological sense used in reading research, the ability to look at written symbols (e.g. letters and words) and translate them into sounds and meanings

LEXICAL - relating to the words of a language

ORTHOGRAPHY - representing spoken language through a set of written symbols

SYNTAX - the way that phrases or sentences are formed by assembling words and other linguistic elements
The human brain is the most complex object in the known universe, and reading is among the most complex tasks it can do. Although most animals, including ourselves, can instinctively communicate with others of their species, we are the only ones that have learnt to do this through writing. "Unlike spoken language skills, learning to read typically requires years of tuition and practice," says Dr Jonathan
Grainger. He works at the French National Centre for Scientific Research (CNRS) and Aix-Marseille University, as a Research Scientist in the Cognitive Psychology Lab, and has made some fascinating insights into how we read.

COMPREHENDING AND DECODING Though some of us find it easier than others, reading is no simple task. Firstly, it involves language comprehension - understanding the underlying language in the first place, which we pick up as infants when we learn to listen and speak. There is then the added element of decoding - taking the symbols we see and translating them into the language we learned to speak. Not everyone is able to do this effectively; people with dyslexia can be competent at spoken language comprehension and highly effective communicators but run into difficulties when trying to decode the words and sentences they see before them.

Reading silently adds another level of complexity, because we are understanding words and sentences without hearing them at all. In fact, silent reading is a relatively new phenomenon and only started to be practised by scholars around the $10^{\text {th }}$ century, whereas written communication dates to about 3500 $B C$. Jonathan explains, "It is thought to be the transition to silent reading that led to the introduction of spaces between words." Indeed, it is silent reading that Jonathan's research currently focuses on.

\section{TRICKYTO TEST}

Psychology has an added challenge compared to most sciences - its subject matter, the mind, 

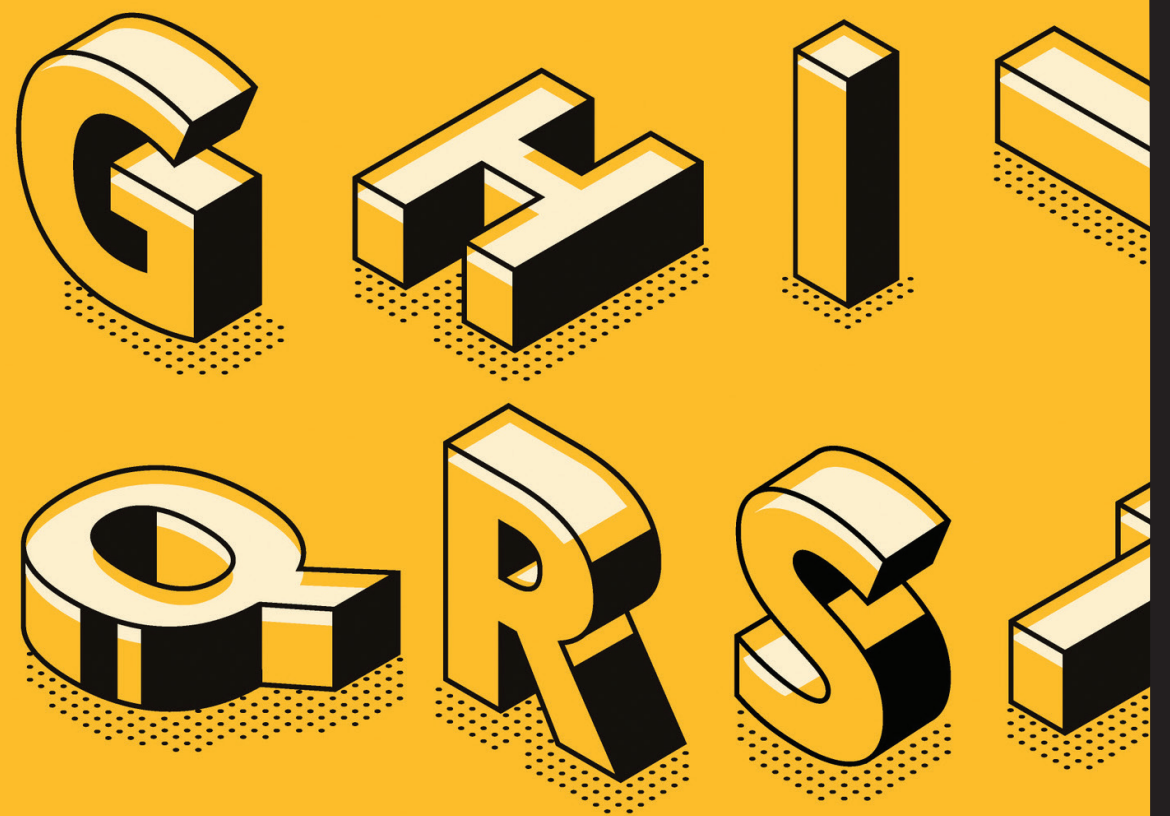

is abstract and virtually impossible to observe directly. For instance, how can we tell exactly what is going on in someone's mind when they are reading silently? Psychological researchers have to get creative with their experimental techniques to answer questions like this.

"To study silent reading, we typically use quite simple laboratory tasks," says Jonathan. "We may ask people to classify letter strings as real words or not (a lexical decision task) or ask them to classify word sequences as grammatically correct or not (a grammatical decision task)." By recording the accuracy of these decisions, and how long it takes participants to make them, Jonathan can infer the cognitive processes going on behind the scenes.

Other research groups use other methods, such as recording the movements of participants' eyes as they silently read and using the recorded patterns to infer the underlying cognitive processes. While it may feel like your eyes are travelling smoothly along a line of text, in fact they are jumping from one point of focus to another about four times every second. By analysing how eye movements change when presented with nonsense sentences, for instance, researchers can get insights into how the brain is processing the information they see on the page. Jonathan has worked with other researchers to bring together these two methods through building computational models of reading, developing a unified framework for understanding reading behaviour.

\section{YOUNG READERS}

Some of Jonathan's work involves studying the reading processes of young children.

"Many children learn to read when they start primary school, and evidence suggests the most progress is made during their first year of school," says Jonathan. Although becoming a skilled reader takes many years, analysing children's reading patterns at this formative age can help uncover the processes that allow us to learn and to identify words and their meanings when we are reading.

Along with other findings, these studies are advancing scientific understanding. "At the basic level, we find a lot of overlap in the mechanisms underlying processing of letters and words," says Jonathan. "However, when we look at how people process words compared to processing sentences, we find major differences." Sentence comprehension relies on syntax - the order of words within a sentence and processing this is a complex task.

\section{DISCOVERIES}

A key way to understanding how reading works is to assess how competent people are at noticing, or overcoming, mistakes. "The transposed-letter effect refers to the jublmed letetrs Ikie this'," says Jonathan. "The transposed-word effect refers to the difficulty we have in detecting the error in sentences like 'you that read wrong again'." These findings suggest that we do not process words letterby-letter, or sentences word-by-word; rather, we process multiple letters or words at the same time, to increase reading efficiency.

People are also better at picking out certain elements in text that makes sense. "The word-superiority effect refers to people finding it easier to identify a single letter when it's within a real word - such as the B in TABLE versus the B in TOBRE," says Jonathan. "The relative ease with which we can read 'txet wtih

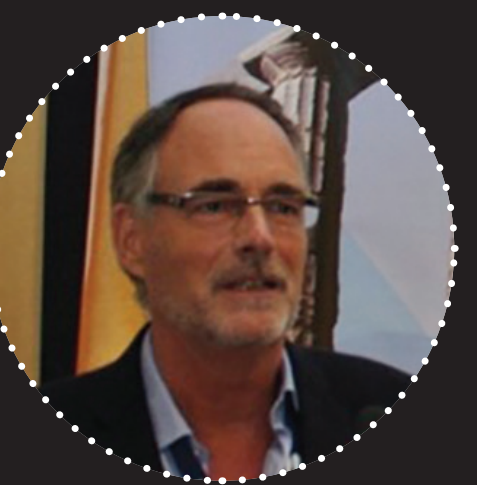

DR JONATHAN GRAINGER

Research Scientist, Cognitive Psychology

Lab, French National Centre for

Scientific Research (CNRS) and AixMarseille University, France

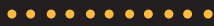

FIELD OF RESEARCH

Cognitive Psychology

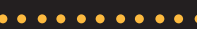

\section{RESEARCH PROJECT}

Using experimental techniques to determine how skilled readers process words and sentences.

...........

FUNDER

European Research Council

sentence-superiority effect refers to the same effect for identifying words in sentences such as the word 'car' in 'this big car is nice' versus 'nice this car big is'."

\section{PROCESSING POWER}

The human brain processes information like a very complex computer. "The ultimate aim of my research is to describe the information processing performed by the brains of skilled readers like a computer program," says Jonathan. "I aim to uncover the mechanisms by which we can rapidly and efficiently extract meaning from extremely complex sequences of visual patterns."

Ultimately, research like this has significant real-world applications. For instance, it may help inform efforts to aid people who have dyslexia, helping them to find cognitive approaches to improve their decoding skills. It may also help inform education syllabuses, particularly for young children, and especially for those struggling to learn to read through conventional methods. It may even help people trying to learn a second language, especially if it is a language that relies on completely different comprehension and decoding techniques to their native tongue. The possibilities are endless. 


\section{ABOUT COGNITIVE PSYCHOLOGY}

WHAT IS COGNITIVE PSYCHOLOGY? Cognitive psychology provides a blueprint of the laws that govern how the mind works - much like how physics establishes the laws of matter. Its foundations lie in analysing behaviour, through methods developed by experimental psychologists. These days, cognitive neuroscience - which uses brain imaging techniques - provides a valuable extension, but behavioural studies remain extremely important.

HAVE THERE BEEN ANY RECENT BREAKTHROUGHS?

Psychological science is a relatively young science and its recent major breakthroughs have mainly been in developing methods to investigate the human mind. The next major breakthrough will likely involve bridging the gap between cognitive theories and neural processing - so rather than just inferring how the mind works from behaviour, actually seeing it through the activity of neurons. This is not to say neural theories will replace cognitive theories but connecting the two will allow major leaps in understanding to take place.

IS FRANCE A GOOD PLACE TO STUDY COGNITIVE PSYCHOLOGY?

France has a strong tradition in experimental psychology and this continues to this day.

Jonathan explains, "We have strong academic departments, which also cater to incoming generations. Both the CNRS and Aix-

Marseille University offer school visits to laboratories and departments, and both are highly active in communicating their research findings to the public."

WHY WOULD WE RECOMMEND A CAREER IN COGNITIVE PSYCHOLOGY?

Cognitive psychology is at the forefront of learning about how we perceive, understand and interact with our environment. It is a fascinating field!

\section{HOW TO BECOME A COGNITIVE PSYCHOLOGIST}

- An undergraduate degree in psychology provides the most straightforward pathway to a career in cognitive psychology, although other subjects such as natural sciences or biology could also lead in the same direction.

- A number of institutions, such as the NHS in the UK, offer apprenticeships in psychology. These tend to focus on clinical psychology more than cognitive psychology but, as an alternative, some universities offer 'degree apprenticeships' that combine part-time studying with employment.

- According to QS World University Rankings, the best universities for psychology are Harvard, Stanford, Cambridge, Oxford and California Berkeley.

- According to Payscale, the average salary for a psychologist in the UK is around $£ 35 \mathrm{k}$. Jonathan points out that salaries in this field can vary widely, however.

5

3

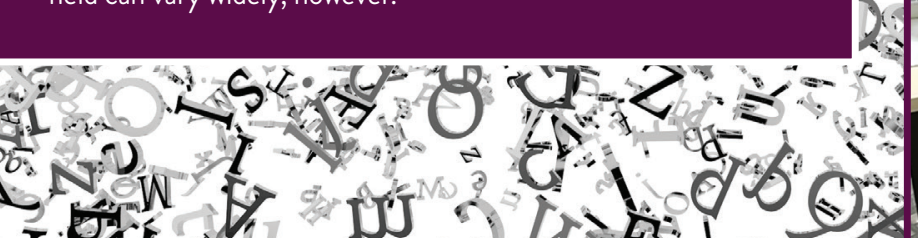$$
\text { . }
$$
s. 得 $\mathrm{Co}=\mathrm{st}$

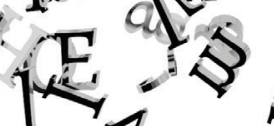
IU⿺ - HOO - HoO tidel a igas

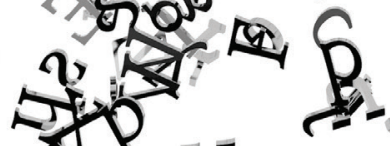
8 $-$ 6

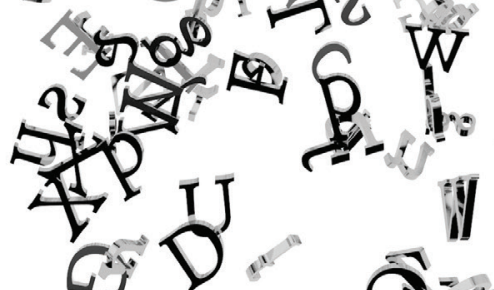
(a)

\section{PATHWAY FROM SCHOOL TO COGNITIVE PSYCHOLOGIST}

Jonathan says that taking maths is an essential at school. Biology, chemistry and physics are also useful for a scientific grounding. Some schools also offer psychology as a subject in itself. Some universities also suggest mixing sciences and humanities for a well-rounded foundation - this could include taking subjects such as English and history. 
